\title{
Correlation Between Bone Metastases and PSA Among Prostate Cancer Patients at Kilimanjaro Christian Medical Centre from June 2018 to May 2019
}

\author{
Samuel Kibona ${ }^{*}$, Orgeness Mbwambo, Nicholaus Ngowi, Frank Bright, Jasper Mbwambo, \\ Alfred Mteta, Mbarouk Mohammed
}

Department of Urology, Kilimanjaro Christian Medical University College, Moshi, Tanzania

\section{Email address:}

ksamd85@gmail.com (S. Kibona), akamteta@gmail.com (A. Mteta), frankbright2001@yahoo.com (F. Bright), jmbwambo05@gmail.com (J. Mbwambo),baltonnic@yahoo.com (N. Ngowi), orgeness@live.com (O. Mbwambo), mbaroukmohd281@gmail.com (M. Mohammed)

*Corresponding author

\section{To cite this article:}

Samuel Kibona, Orgeness Mbwambo, Nicholaus Ngowi, Frank Bright, Jasper Mbwambo, Alfred Mteta, Mbarouk Mohammed. Correlation Between Bone Metastases and PSA Among Prostate Cancer Patients at Kilimanjaro Christian Medical Centre from June 2018 to May 2019. International Journal of Clinical Urology. Vol. 5, No. 1, 2021, pp. 47-50. doi: 10.11648/j.ijcu.20210501.20

Received: November 21, 2020; Accepted: December 9, 2020; Published: June 9, 2021

\begin{abstract}
Prostate cancer is a leading cause of cancer death in men, second only to lung cancer. Bone metastasis is a common complication in prostate cancer patients that can cause bone pain and pathological fracture. PSA, Gleasons score, clinical $\mathrm{T}$ stage have been developed to integrate multiple clinical metastatic disease in prostate cancer patients. Bone radiography is used to rule out bone metastasis. It's common to have bone metastasis when PSA level is high and histology of poorly differentiated adenocarcinoma. Aim: To determine the prevalence of osteoblastic lesions and analyze the correlation of PSA levels, on lumbar sacral radiography in patients diagnosed with prostate cancer. Methods: This was a hospital based crosssectional retrospective study, conducted at KCMC urology institute from June 2108 to May 2019 and all prostate cancer patients diagnosed at KCMC during the study period both inpatients and outpatients attending urology department within the study period. The structural data sheet was used to collect information from patient file. Study parameters include Age, Gleason's score, PSA level used to assess the correlation with osteoblastic lesion on lumbar sacral x-ray. Results: A total of 97 patients included in the study, with mean age was 74.5 (SD) 8.97.6 yrs. Patients with Gleason score of 8-10 were 56 (57.8\%) and the median PSA level was $126 \mathrm{ng} / \mathrm{mL}$ with IQR (58.9-402.2) and The prevalence of bone metastases was $57.7 \%$. There were $56(49.5 \%)$ patient had osteoblastic lesions on lumbar sacral x-ray with PSA $>100$. Conclusion: The prevalence of bone metastasis is $57.7 \%$ with $49.5 \%$ of the patients had total serum PSA of $>100 \mathrm{ng} / \mathrm{mL}$. So lumbar sacral X ray can be used as a diagnostic tool when PSA is more than $100 \mathrm{ng} / \mathrm{ml}$. There is a need to avoid unnecessary lumbar sacral X rays in patients with carcinoma of the prostate who have no symptoms and sign metastatic disease and has PSA of less than $100 \mathrm{ng} / \mathrm{ml}$.
\end{abstract}

Keywords: Bone Metastases, PSA, Prostate Cancer

\section{Introduction}

Prostate cancer is a leading cause of cancer death in men, second only to lung cancer [1]. Bone metastasis is a common complication in prostate cancer patients that can cause bone pain and pathological fracture. Bone is a common target of distant metastases in prostate cancer. Other cancers of lung, kidney and breast also present with metastases to the bone. However prostate cancer is unique in that bone is often the only clinically detectable site of metastasis, and the resulting tumours tend to be osteoblastic (bone forming) rather than osteolytic (bone lysing). The Plain radiographs (X-rays) demonstrate characteristic osteoblastic lesions [2].

Most of our patients present in our clinics with advanced prostate cancer came late at the clinic and in which the Lumbosacral metastasis is the one of the common metastatic site. PSA is being used to monitor progress of the disease and 
Gleason score from histology for diagnosis of prostate cancer. Bone radiography is common used to rule out bone metastasis. It's common to have bone metastasis when PSA level is high and histology of poorly differentiated adenocarcinoma The American Urology Association (AUA) and the European Association of Urology guidelines for prostatic carcinoma suggest that bone scan may not be indicated in patients with a PSA level of $<20 \mathrm{ng} / \mathrm{ml}$ or less [3].

In our setting bone radiography is being done routinely to all patient diagnosed with prostate cancer so as to rule out metastasis which increases cost and burden to the patient. We don't have cut off point of PSA when to avoid lumbar sacral $\mathrm{X}$-ray in patients with prostate cancer Radionuclide bone scan (bone scintigraphy) is the most sensitive modality for the detection of skeletal metastases [4]. Bone survey films (skeletal radiography) have lower sensitivity for the identification of distant spread. But due difficult in accessing bone scan we still use plain $\mathrm{X}$ rays in diagnosing patient with bone metastases.

The aim of the study was done to show how the PSA correlates with the findings on lumbar sacral $\mathrm{X}$ ray among patients diagnosed with prostate cancer. Therefore, it will help to avoid routine bone imaging in patients with no suspect of osteoblastic bone metastases. PSA level will help to predict possibility of metastasis in our patient diagnosed with prostate cancer [4].

\section{Methods}

\subsection{Study Design}

This was Cross-sectional hospital based Retrospective study involving patients at KCMC from June 2018 to May 2019. A structured data sheet was used to collect information from the patient's files and films. Study parameters include Age, Gleason's score, PSA level used to assess the correlation with bone metastasis.

\subsection{Study Population}

This study was conducted at KCMC which is a zonal referral hospital receiving patients mainly from districts and regional hospitals from northern parts of Tanzania mainland and neighboring countries like Kenya with population of more than 10 million people. Prostate cancer patients diagnosed at KCMC during the study period both inpatients and outpatients attending urology department within the study period.

Exclusion of other malignancies that could metastases to the lumbar sacral vertebra lung and breast cancer or patients Paget's disease who also presents with osteoblastic lesions also absence of needed data.

\subsection{Outcomes and Explanatory Variables}

The main study Dependent variable was PSA and independent was osteoblastic bone lesions.

\subsection{Statistical Analysis}

Collected data were reviewed and then entered, managed, and analyzed by SPSS (Statistical Package for the Social Sciences). Bivariate analysis was done to show relationships between PSA and bone metastasis (osteoblastic lesions) and Statistically significance was set at $p$ value of $<0.05$.

\subsection{Ethical Consideration}

Ethical clearance was sought from KCMUCo ethical committee and given number 2304 patient information was handled in privacy and confidentiality patient names were not used instead individual identification number were used.

\section{Results}

There were 106 patients with prostate cancer enrolled in the study and 97 were included in the final analysis. We excluded 9 patients from final analysis because they did not have X-rays. Table 1: Socio-demographic and clinical characteristics of study participants of the 97 participants included in the study, the mean age was 74.2yrs (SD8.97). Majority $56(57.8 \%)$ had a Gleason score 8-10 and patients with PSA $>100$ was 57 (58.8\%).

Table 1. Socio-demographic and clinical characteristics of study participants $(n=97)$.

\begin{tabular}{ll}
\hline Characteristic & $\mathbf{N}(\%)$ \\
\hline Age & $2(2.1)$ \\
$<60$ & $30(30.9)$ \\
$61-70$ & $44(45.5)$ \\
$71-80$ & $21(21.6)$ \\
$>81$ & $74.2(8.97)$ \\
Mean (SD) & \\
Gleason score & $8(8.2)$ \\
$<6$ & $33(34.0)$ \\
7 & $56(57.8)$ \\
$8-10$ & \\
PSA level & $6(6.2)$ \\
$<10$ & $7(7.2)$ \\
$11-20$ & $9(9.3)$ \\
$21-50$ & $18(18.6)$ \\
$51-100$ & $57(58.8)$ \\
$>100$ & $126(58.9-402.2)$ \\
Median (IQR) & \\
\hline
\end{tabular}

The median PSA level and IQR was 126 (58.9402.2) ng/ml.

Figure 1: show the Prevalence of Osteoblastic Lesions among 97 study participants, 56 had osteoblastic lesions on radiographic films accounted for $57.7 \%$ ).

Table 2: Indicates correlation between PSA level and osteoblastic lesion out of 56 study participants who were found to have osteoblastic lesion $48(49.5 \%)$ had PSA level $>100$. 


\section{Prevalence of Osteoblastic lesion}

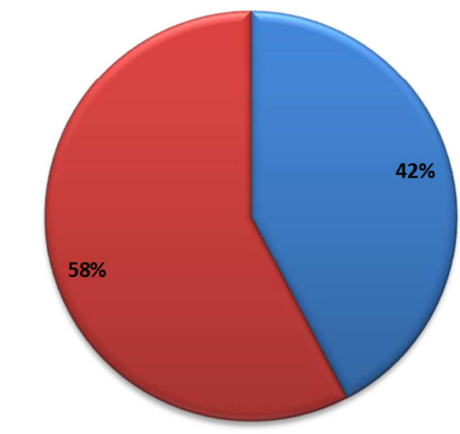

Figure 1. Prevalence of osteoblastic lesion $(n=97)$.

Table 2. Correlation between PSA and Osteoblastic lesions $(n=56)$.

\begin{tabular}{|c|c|c|}
\hline \multirow{2}{*}{ PSA LEVEL } & Osteoblastic lesion & \multirow{2}{*}{ p-value } \\
\hline & Yes & \\
\hline$<10$ & $0(0)$ & - \\
\hline $11-20$ & $0(0)$ & - \\
\hline $21-50$ & $2(2.1)$ & 0.99 \\
\hline $51-100$ & $6(6.2)$ & 0.55 \\
\hline$>100$ & $48(49.5)$ & 0.001 \\
\hline
\end{tabular}

\section{Discussion}

\subsection{Prevalence of Prostate Cancer Bone Metastasis}

In this study the prevalence of bone metastasis was found to be $57.7 \%$ and majority of patient with osteoblastic lesion were aged between 71-80 our study shows participants who were found to have osteoblastic lesion 48 (49.5\%) had PSA level $>100$. This finding is similar to the study done in Texas which show the prevalence of bone metastasis was $82 \%$ with PSA level $>100 \mathrm{ng} / \mathrm{ml}$ [5].

There is much variation with the study done in Cameroon and Uganda where the prevalence of bone metastasis was around $30 \%$ with average PSA $43.23 \mathrm{ng} / \mathrm{ml}$ and $18 \%$ with mean age 69.5 years respectively $[6,7]$.

\subsection{Correlation Between PSA and Osteoblastic Lesion}

In this study correlation between PSA and osteoblastic lesion was found to be statistically significant when PSA of more than hundred $(>100 \mathrm{ng} / \mathrm{mL})$ which mean you can predict bone metastasis. This finding is consistent with the study done Edinburg where by pre-operative serum PSA ( $>$ $100 \mathrm{ng} / \mathrm{ml}$ ) was the single most important indicator of metastatic disease, with $100 \%$ predictive value and the same finding from India where they found that patients with PSA > $100 \mathrm{ng} / \mathrm{ml}$ out of 110108 had skeletal metastases and similar finding was observed from china all patients with PSA $>100 \mathrm{ng} / \mathrm{ml}$ had M1 disease [8-10].

There were no patients with PSA of less than 20 who had bone metastasis and only 2 patients out of 9 who had PSA of 21 to $50 \mathrm{ng} / \mathrm{mL}$ who had osteoblastic lesions on lumbar sacral radiography which statistically was insignificant. This finding was similar to the study done in Netherlands which show that out of 144 patients with prostate cancer and a PSA level of $<20 \mathrm{ng} / \mathrm{ml}, 19$ had positive bone scan (13\%) [11].

PSA level of 51 to $100 \mathrm{ng} / \mathrm{mL}$ only 6 patients out of 18 had metastasis which also was statistically insignificant. This study was same to a study done in UK and India where by a PSA levels $>58 \mathrm{ng} / \mathrm{ml}$ are highly indicative of spread to the skeleton and PSA of $20-100 \mathrm{ng} / \mathrm{ml}$ out of 47 patients 42 had skeletal metastasis while only 3 patients out of 113 with PSA below $20 \mathrm{ng} / \mathrm{ml}$ had skeletal metastases respectively $[12,13]$.

Our study was different to other study done in Mexico which showed that association of an increase in PSA and disseminated disease, it was documented that an increase in PSA above $10 \mathrm{ng} / \mathrm{mL}$ is highly suggestive of metastatic disease This difference can be due to less sensitivity $\mathrm{X}$ ray and whereby in china a serum PSA concentration of $13 \mathrm{ng} / \mathrm{ml}$ gave the best sensitivity (96.43\%) and specificity (84.09\%) $[14,15]$.

\section{Conclusion}

The prevalence of bone metastasis is $57.7 \%$ with $50 \%$ of the patients had total serum PSA of $>100 \mathrm{ng} / \mathrm{mL}$. So lumbar sacral $X$ ray can be used as a diagnostic tool when PSA is more than $100 \mathrm{ng} / \mathrm{ml}$. There is a need to avoid unnecessary the lumbar sacral $X$ rays in patients with carcinoma of the prostate who have no symptoms and sign metastatic disease and has PSA of less than $100 \mathrm{ng} / \mathrm{ml}$.

\section{Recommendation}

Even though plain $\mathrm{X}$ rays are less sensitive we can still use in limited resource countries when PSA is more than 100.

\section{List of Abbreviations}

ADT: Androgen Deprivation Therapy

AR: Androgen Receptor

DRE: Digital Rectal Examination

KCMUCo: Kilimanjaro Christian Medical University college

KCMC: Kilimanjaro Christian Medical Centre

LHRH: Luteinizing Hormone Releasing Hormone

PCA: Prostate Cancer

PSA: Prostate Specific Antigen

TCB: Tru Cut biopsy

TRUSS: Trans Rectal Ultrasound

\section{Declarations}

\section{Ethical Approval}

Research ethical clearance was received from the KCMUCO Research and Ethical committee (certificate no 2304), patient informed consent was not required due to the anonymized patient data, and that it was conducted in accordance with the Declaration of Helsinki and permission was obtained from the head of Urology Institute. 
Consent for publication.

I Dr. Samuel Kibona hereby declare, I participated in the study and development of manuscript entitled "Correlation between bone metastases and PSA among prostate cancer patients at Kilimanjaro Christian Medical Centre from June 2018 to May 2019: I have read the final version and give consent to be published in International Journal of $\mathrm{C}$ linical Urology.

\section{Competing Interests}

The authors declare that they have no competing interests.

\section{Contributors}

The IPH department and Urology Institute conceptualized and designed the study, conducted the statistical analysis, drafted the initial manuscript and approved the final manuscript as submitted.

\section{Acknowledgements}

To the Institute of Urology for permission to publish the findings of this study to all residents in urology for tireless selfless effort to ensure that I complete this study in time and with great precision. Special thanks to Dr Debora from pediatrics for Data analysis and Dr Litte from radiology department for reading and interpreting lumbar Sacral X rays

\section{References}

[1] Abouassaly R, Thompson IM, Platz EA, Klein EA. Epidemiology, Etiology, and Prevention of Prostate Cancer [Internet]. Tenth Edit. Campbell-Walsh Urology. Elsevier Inc.; 2012. 2704-2725. e7 p. Available from: http://linkinghub.elsevier.com/retrieve/pii/B978141606911900 0955 .

[2] Logothetis CJ, Lin SH. Osteoblasts in prostate cancer metastasis to bone. Nat Rev Cancer. 2005; 5 (1): 21-8.

[3] Metastasis B, Pai K, Salgaonkar G, Kudva R, Hegde P. Diagnostic Correlation between Serum PSA, Gleason Score and Bone Scan Results in Prostatic Cancer Patients with. 2015.

[4] Loeb S, Carter HB. Early Detection, Diagnosis, and Staging of Prostate Cancer [Internet]. Tenth Edit. Campbell-Walsh Urology. Elsevier Inc.; 2012. 2763-2770. e7 p. Available from:
http://linkinghub.elsevier.com/retrieve/pii/B978141606911900 0992.

[5] Ganeshan D, Aparicio AM, Morani A, Kundra V. Pattern and distribution of distant metastases in anaplastic prostate carcinoma: A single-institute experience with 101 patients. Am J Roentgenol. 2017; 209 (2): 327-32.

[6] Jones GW. Diagnosis and management of prostate cancer. Cancer. 1983; 51 (12 S): 2456-9.

[7] Okuku F, Orem J, Holoya G, De Boer C, Thompson CL, Cooney MM. Prostate Cancer Burden at the Uganda Cancer Institute. J Glob Oncol. 2016; 2 (4): 181-5.

[8] Sanjaya IPG, Mochtar CA, Umbas R. Correlation between low Gleason score and prostate specific antigen levels with incidence of bone metastases in prostate cancer patients: when to omit bone scans? Asian Pac J Cancer Prev [Internet]. 2013; 14 (9): 4973-6. Available from: http://www.ncbi.nlm.nih.gov/pubmed/24175761.

[9] RANA A, KARAMANIS K, LUCAS MG, CHISHOLM GD. Identification of Metastatic Disease by T Category, Gleason Score and Serum PSA Level in Patients with Carcinoma of the Prostate. Br J Urol. 1992; 69 (3): 277-81.

[10] Wei RJ, Li TY, Yang XC, Jia N, Yang XL, Song HB. Serum levels of PSA, ALP, ICTP, and BSP in prostate cancer patients and the significance of ROC curve in the diagnosis of prostate cancer bone metastases. Genet Mol Res. 2016; 15 (2).

[11] Wymenga LFA, Boomsma JHB, Groenier K, Piers DA, Mensink HJA. Routine bone scans in patients with prostate cancer related to serum prostate-specific antigen and alkaline phosphatase. BJU Int. 2001; 88 (3): 226-30.

[12] Kamaleshwaran KK, Mittal BR, Balasubramanian CN. Predictive value of serum prostate specific antigen in detecting bone metastasis in prostate cancer patients using bone scintigraphy. 2012; 27 (2).

[13] PANTELIDES ML, BOWMAN SP, GEORGE NJR. Levels of Prostate Specific Antigen that Predict Skeletal Spread in Prostate Cancer. Br J Urol. 1992; 70 (3): 299-303.

[14] Wei LH, Chiu JS, Chang SY, Wang YF. Predicting Bone Metastasis in Prostate Cancer Patients: Value of Prostate Specific Antigen. Tzu Chi Med J [Internet]. 2008; 20 (4): 291-5. Available from: http://dx.doi.org/10.1016/S10163190(08)60053-1.

[15] $\mathrm{Jj} \mathrm{H}, \mathrm{Jj} \mathrm{O}$, Le G. Correlation between increase in prostatespecific antigen and metastatic lesions identified by. 2016; 15 (2): 88-92. 